\title{
Influence of Thermal Aging on the Winding Thermal Conductivity in Low Voltage Electrical Machines
}

\author{
Vincenzo Madonna ${ }^{1 *}$, Paolo Giangrande ${ }^{1}$, and Michael Galea ${ }^{1,2}$ \\ ${ }^{1}$ Power Electronics, Machines and Control Research Group (PEMC), University of Nottingham, UK \\ ${ }^{2}$ Key Laboratory of More Electric Aircraft Technology of Zhejiang Province, Ningbo, China \\ *Email: Vincenzo.Madonna1@nottingham.ac.uk
}

\begin{abstract}
It is widely acknowledged that thermal aging can have a detrimental effect on the reliability and lifetime expectancy of electrical machines. Long exposure times to high temperature can deteriorate the dielectric properties of the electrical insulation system. At the same time, high temperature can strongly affect thermo-physical properties of polymeric materials, which are commonly employed for the insulation system of low voltage motors. This work experimentally investigates what is the effect of thermal aging on the winding equivalent thermal conductivity in low voltage electrical machines. The life results of accelerated thermal aging tests, carried out on suitable specimens, are processed through a Weibull-Bayesian approach. The variation of the equivalent winding thermal conductivity with thermal aging is ultimately correlated to the cumulative thermal aging of the insulation system.
\end{abstract}

Index Terms-Physics of Failure, Design of Experiments, Design of Insulation, Electrical Machines, Thermal Management

\section{INTRODUCTION}

Thermal management plays a critical part in the design and operation of electrical machines (EMs) [1-3]. An excellent cooling system [4-6] and / or the adoption of suitable materials with low thermal conductivity [7], can guarantee a) appropriate reliability levels (i.e., low failure probability) [8] and b) possibility to achieve high torque / power densities [9, $10]$. Both these requirements need to be mandatorily satisfied in EMs designed for high performance applications, such as those employed in (more) electrified transportation [11-13].

In conventional EMs, the winding is generally the hottest spot, as most of the losses are concentrated within its volume [14]. On top of that, the thermal aging of the winding insulation system (mainly the interturn insulation) is one of the major initiators of stator failures $[15,16]$. Accordingly, a proper thermal management of the winding is essential for guaranteeing a satisfactory lifespan, characterized by low failure probability [17].

A main "thermal barrier" between the hot-spot temperature within an EM winding and the cooling agent is represented by the winding thermal conductivity $k_{w}$ in the radial and tangential directions [18-20]. Because the winding can be

This work was partially funded from the Clean Sky 2 Joint Undertaking under the European Union's Horizon 2020 research and innovation programme under grant agreement no. 807081.

This work was also partially funded by the University of Nottingham Propulsion Futures Beacon. (Corresponding Author: Vincenzo Madonna)

V. Madonna, P. Giangrande and M. Galea are with the Power Electronics, Machines and Control Research Group (PEMC), University of Nottingham, UK. (email: Vincenzo.madonna1@nottingham.ac.uk)

M. Galea is also with the Key Laboratory of More Electric Aircraft Technology of Zhejiang Province, Ningbo 315100, China. seen as a compound of copper, insulating enamel and resin impregnation, $k_{w}$ can be some orders of magnitude lower than the pure copper conductivity. Thus, when thermally-modeling a newly designed EM, the precise $k_{w}$ estimation is crucial for an accurate hot-spot temperature prediction.

When designing (or thermally-assessing) a new EM, it is common practice to assume a fixed $k_{w}$ value throughout the whole machine lifetime [21-23]. This typical methodology implicitly assumes that thermo-physical properties of insulating materials within the EM's insulation system are invariant with thermal aging. In other words, regardless the extent of thermal aging, it is generally accepted that properties such as the thermal conductivity of materials constituting an EM stay unchanged despite a cumulative exposure to high temperature (throughout the machine's life). Recent publications [24, 25] have however reported that dielectric properties of insulation sub-systems within electrical machines tend to be strongly influenced by the degree of thermal aging.

This paper aims in demonstrating that assuming a nonvariant winding thermal conductivity, throughout the EM insulation system's lifetime, can potentially lead to inaccurate outcomes. For doing so, initially, the results of accelerated thermal aging tests, performed on suitable specimens emulating a typical low voltage EM, are presented. These are processed through a Weibull-Bayesian approach for deriving the thermal endurance curve of the interturn insulation system. The latter allows to estimate the time to failure of the insulation system exposed to any temperature (within the limits of a single-reaction Arrhenius model). The postprocessed life data are then employed for predicting how the numerical value of the winding equivalent thermal conductivity evolves throughout the lifetime of a typical EM.

\section{THERMAL AgING TeStS}

Accelerated thermal aging tests have been carried out on a set of 5 motorettes which are shown in Fig. 1. Each motorette has a total of 6 coils, wound around three teeth, and a single coil comprises two strands of $0.4 \mathrm{~mm}$ diameter magnet wire, with a class 200, grade 2 insulation. The adoption of two parallel strands enables the dielectric assessment of the interstrand insulation, which for a low voltage EM is equivalent to the turn-to-turn insulation layer. Each motorette is vacuum pressure impregnated with an epoxy-based resin for high temperature applications.

The specimens are thermally aged in an environmental chamber through exposure cycles of 60 hours at a temperature of $230{ }^{\circ} \mathrm{C}$. After each exposure cycle, an $\mathrm{AC}$ electric withstand test is performed on the interstrand insulation of 
each of the 30 sub-coils (i.e. 6 per motorette). Throughout the diagnostic session, a test voltage of $500 \mathrm{Vrms}, 50 \mathrm{~Hz}$ is applied to the specimen for a short time duration, so that the insulation is not electrically stressed by partial discharges [26, 27] during the assessment. The failure times are progressively recorded, and the test concludes when all the specimens are categorized as 'failed'.

The interval-censored Weibull probability plot of failure times is reported in Fig. 2. It is possible to note that the selected statistical distribution shows an excellent fit with the clustered life data.

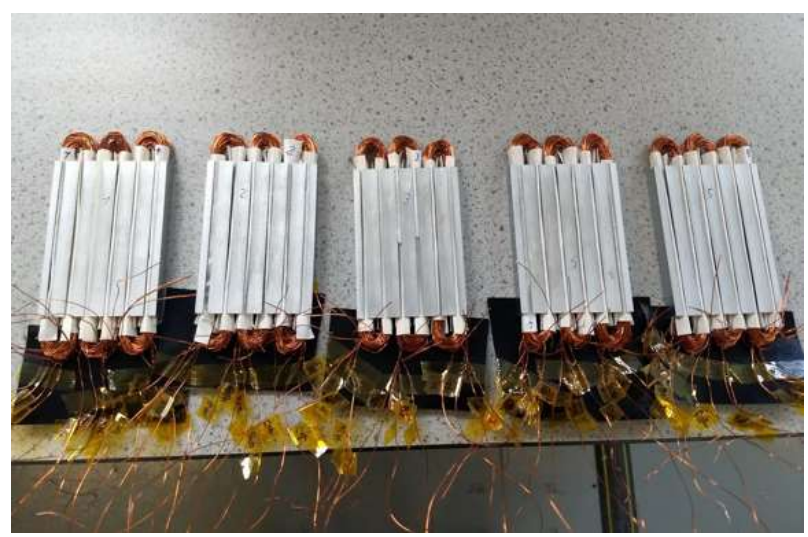

Fig. 1. Random wound motorettes employed for the thermal aging campaign.

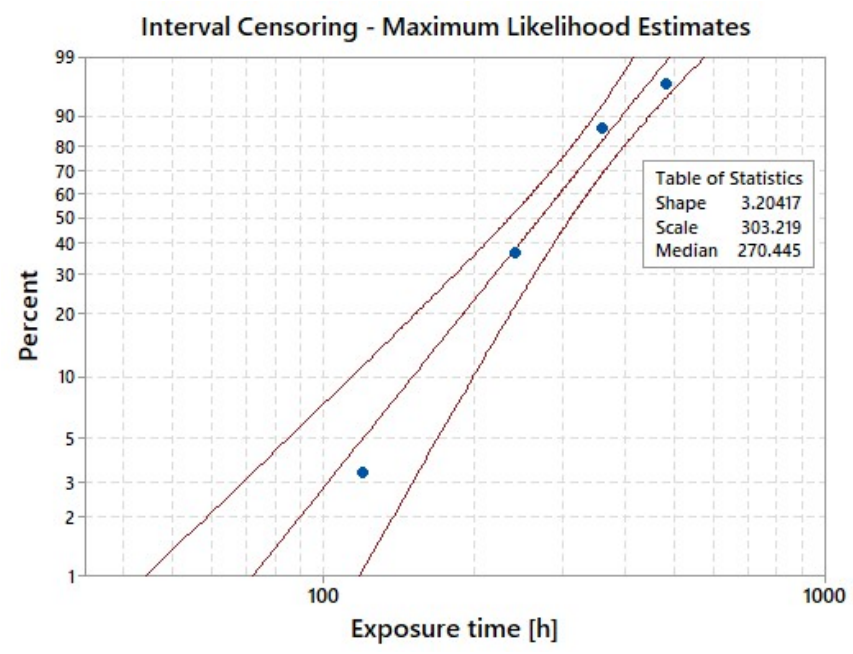

Fig. 2. Weibull probability plot of failure times for the thermally aged specimens.

The standardized methodology, for extracting the thermal endurance curve of electrical insulating materials and systems, would require replicating the thermal aging campaign for two additional temperatures (other than $230^{\circ} \mathrm{C}$ ), and the three temperatures should be separated by a $20^{\circ} \mathrm{C}$ interval (between each other). In this work a different approach is used, namely, the failure times at aging temperatures of 210 and $190{ }^{\circ} \mathrm{C}$ are predicted through a Weibull-Bayesian [28] approach and Monte Carlo simulations. The proposed approach is valid if the two following assumptions hold true:

1. The failure mode stays unchanged when the aging temperature is modified [29];

2. The insulation thermal life follows the so-called Montsinger's rule (i.e. the insulation life halves every time the temperature increases by $H I C{ }^{\circ} \mathrm{C}$, where $H I C$ generally lies between 7 and $15^{\circ} \mathrm{C}$ ) [30].

If the insulation temperature is such that secondary chemical reactions are not triggered, then condition 1) is fulfilled. This implies that the failure times for specimens aged at temperatures below $230{ }^{\circ} \mathrm{C}$, would be Weibull-distributed, with a shape factor $\approx 3.2$ (cfr. Fig. 2). Indeed, the Weibull shape (i.e. slope) is strictly correlated with the specimens' failure mode. The only unknown(s) then would be the Weibull scale factor. Here is where the assumption number 2) comes into play. Its significance can be summarized by (1), where $L\left(\theta_{k}\right)$ is the lifetime at temperature $\theta_{k}$ (for a selected failure probability, and end-of-life criterion).

$$
L\left(\theta_{2}\right)=L\left(\theta_{1}\right) \cdot 2^{\frac{\theta_{1}-\theta_{2}}{H I C}}
$$

Previous experience has confirmed that the thermal lifetime of typical polymeric materials employed in low voltage EMs are satisfactorily predicted by (1) [30].

In view of the above, two Weibull probability distributions of failure times can be generated - one relative to $210{ }^{\circ} \mathrm{C}$ and the other relative to $230{ }^{\circ} \mathrm{C}$ aging temperatures respectively. Both of them will have a shape factor equal to 3.2 , whilst the scale factor is calculated through (1) (i.e. a $63.2 \%$ failure probability is assumed and $\mathrm{HIC}$ is fixed to $10{ }^{\circ} \mathrm{C}$ ). A random number generator, implemented in Minitab ${ }^{\circledR}$, is adopted for the purpose, by simulating 100 Weibull-distributed failure points for each temperature. The resulting parallel Weibull probability plots are reported in Fig. 3. Accordingly, it is now possible to obtain the (expected) thermal endurance plot of the interturn insulation [17], as shown in Fig. 4.

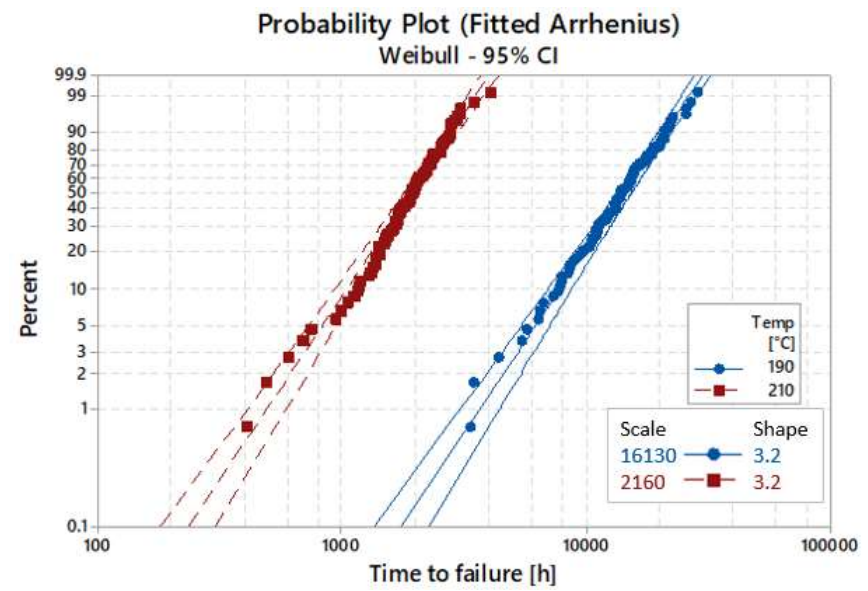

Fig. 3. Weibull-distributed failure points from Monte Carlo simulations.

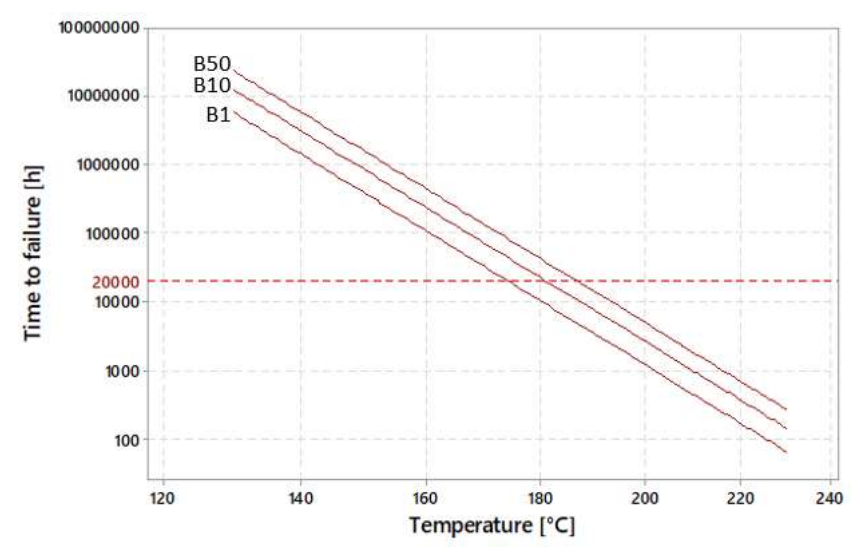

Fig. 4. Thermal endurance plot (or Arrhenius curve) of the interturn insulation system.

\section{Cumulative Damage}

The linear damage law, or Miner's rule, is adopted for estimating the insulation cumulative damage (i.e. consumed lifetime fraction) within a generic time-interval of thermal exposure at given temperature(s). The per-unit cumulative 
damage experienced by an insulation system exposed to a given temperature $\theta_{j}$ for a time-span $\tau$ can be calculated according to (2).

$$
D_{\tau}\left(\theta_{j}\right)=\int_{0}^{\tau} \frac{1}{L\left(\theta_{j}\right)} d t=\frac{\tau}{L\left(\theta_{j}\right)}
$$

The lifetime $L\left(\theta_{j}\right)$ can be straightforwardly obtained from the thermal endurance curve (i.e. Fig. 4), in case of constant temperature operations, by selecting a suitable probability of failure (i.e. $B x$ in Fig. 4) according to the desired reliability level. Or alternatively it can be calculated through a suitable lifetime prediction model in case of time-variant temperature profiles [31].

Taking the case of the analyzed interturn insulation subsystem, exposed for 10,000 hours to a constant temperature of $180{ }^{\circ} \mathrm{C}$, its cumulative damage at $10 \%$ failure probability would be calculated as in (3).

$$
D_{10,000 h}\left(180^{\circ} \mathrm{C}\right)=\int_{0}^{10,000 h} \frac{1}{20,000 h} d t=0.5
$$

In other words, after 10,000 hours the insulation exposed continuously to $180{ }^{\circ} \mathrm{C}$ would have "consumed" half of its lifetime (at $10 \%$ failure probability, or B10). To note that '20,000 hours' in (3) has been obtained from Fig. 4 by considering the interception of the B10 thermal endurance curve with the temperature $180^{\circ} \mathrm{C}$.

\section{Thermal AgING AND HEAT DissiPATION}

In this Section, experimental tests are performed for analyzing how the thermal behavior (i.e. capability of heat dissipation) of a typical low voltage EM is influenced by the degree of thermal aging of its insulation system. For doing so, random wound motorettes - whose geometry, winding layout and materials are identical to those employed throughout the thermal aging campaign presented in Section II - have been used. Four thermocouples have been embedded within the motorettes' winding, prior varnishing. The exact location of the thermal sensors is suitably selected for capturing the hotspot temperature, thanks to a preliminary thermal signature analysis (i.e. thermography), as shown in Fig. 5. Further, two additional thermocouples (i.e. one for each of the two motorettes) have been positioned over the motorettes' external housing / core surface.

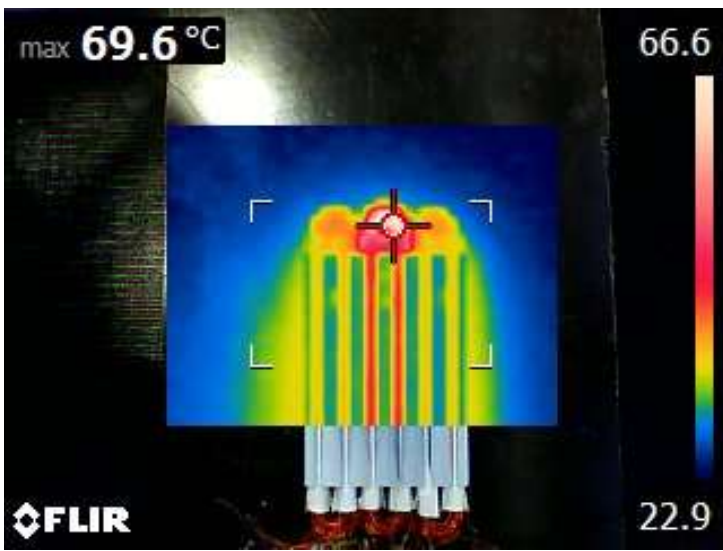

Fig. 5. Thermal signature analysis of a motorette fed through DC current.

The two unaged motorettes have been positioned in a thermal environmental chamber and their coils have been series connected. After setting an ambient temperature of $30{ }^{\circ} \mathrm{C}$, and waiting for thermal equilibrium, the winding is fed through a $1.5 \mathrm{~A}$ DC current, via a programmable power supply. The winding temperature profile, as well as the housing's one, are recorded through a temperature data-logger connected to a personal computer. The thermal steady-state condition is reached after ca. 1.5 hours, and the resulting temperature profiles are reported in Fig. 6.

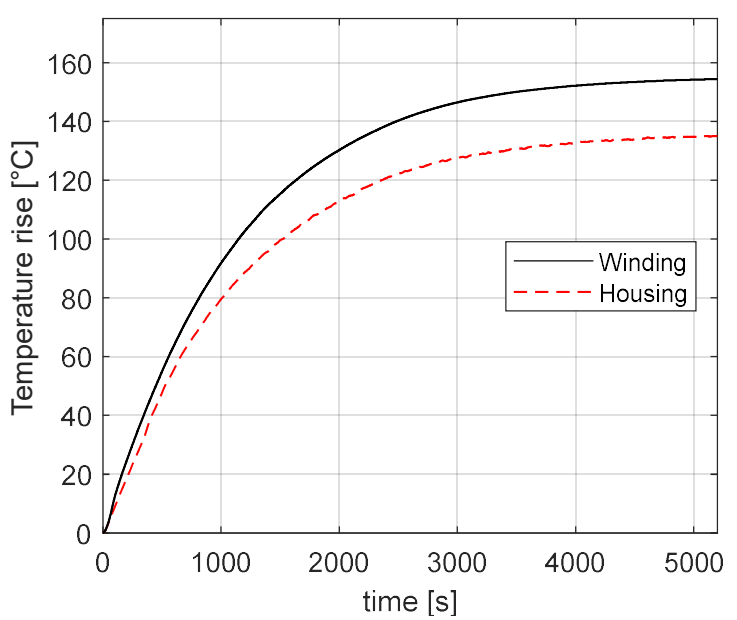

Fig. 6. Motorette's temperature profile with 1.5 A DC current excitation.

At this point the motorettes are subjected to a series of thermal aging cycles at $230{ }^{\circ} \mathrm{C}$, shortly followed by the abovedescribed thermal characterization session. The whole procedure is detailed in Fig. 7.

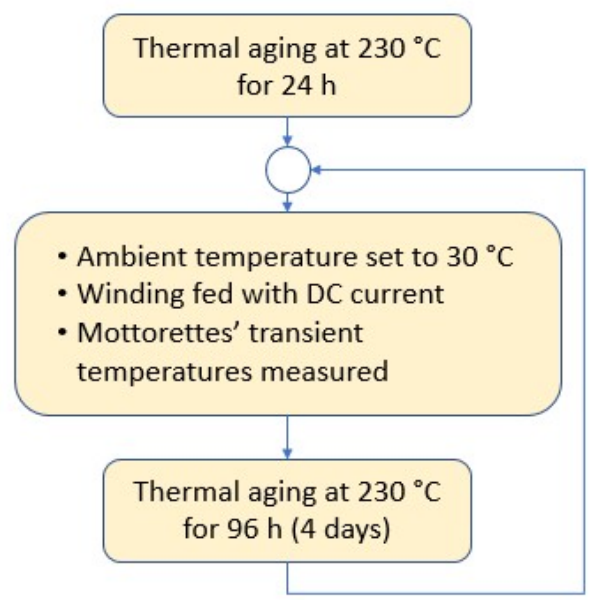

Fig. 7. Flow chart of the experimental thermal evaluation procedure.

The resulting steady state, hot-spot temperatures (at various aging levels) are presented in Table I. It is clear that the thermal aging has an influence on the thermal behavior of the motorette. Indeed, the hot-spot temperature (recorded by feeding the winding through a $1.5 \mathrm{~A}$ DC current) tends to increase with the cumulative thermal aging.

TABLE I

Slot Measured Temperature vs. Thermal Aging

\begin{tabular}{cc}
\hline \hline $\begin{array}{c}\text { Thermal exposure } \\
\text { time at } 230\end{array}$ & $\begin{array}{c}\text { Steady-state hot-spot } \\
\text { Temperature }\left[{ }^{\circ} \mathbf{C}\right]\end{array}$ \\
\hline $0 h$ (unaged) & 154 \\
$24 h$ & 159 \\
$120 h$ & 163 \\
$216 h$ & 168 \\
$312 h$ & 171 \\
\hline \hline
\end{tabular}

This variation is to be ascribed to the change in thermal conductivity of the winding's insulation system (i.e. wire enamel and impregnating resin), caused by the thermal aging. For quantifying the numerical variation of the winding radial and tangential thermal conductivity, a 2D thermal finite element (FE) model of a single slot is built in $\operatorname{ANSYS}^{\circledR}$ as 
shown in Fig. 8. The slot is thermally modelled as a single material, whose conductivity is $k_{w}$. A sequential quadratic programming algorithm is implemented in $\mathrm{Matlab}^{\circledR}$ for selecting suitable $k_{w}$ values, allowing the FE-modelled hotspot temperature to match the experimentally recorded one, for various thermal aging levels. An example of simulation result is shown in Fig. 9, which refers to the unaged motorette. A good match with the experimentally measured temperatures can be noted (cfr. steady state temperatures of Fig. 6). The model's accuracy can be verified in Fig 10 where measured and FE-predicted temperatures are apprised. The corresponding $k_{w}$ values, after the various thermal exposure cycles at $230{ }^{\circ} \mathrm{C}$, are listed in Table II.

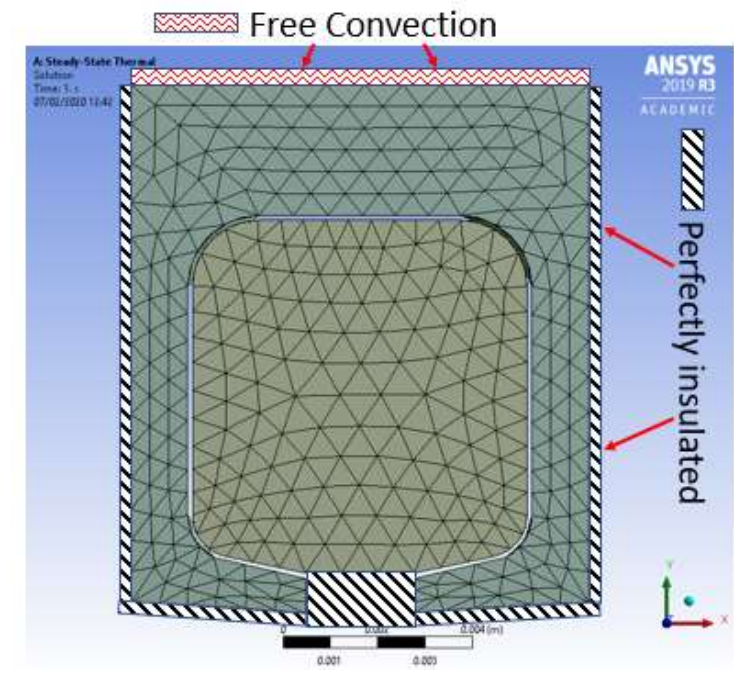

Fig. 8. Thermal FE model of the PMSM slot: geometry, mesh and boundary conditions.

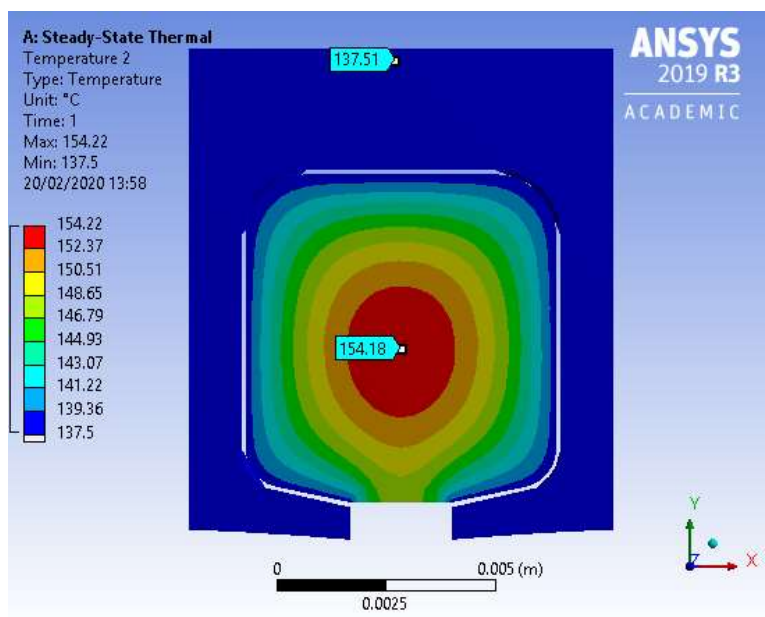

Fig. 9. Result from thermal FE simulation when the excitation current is 1.5 $\mathrm{A}$, and the winding insulation is unaged.

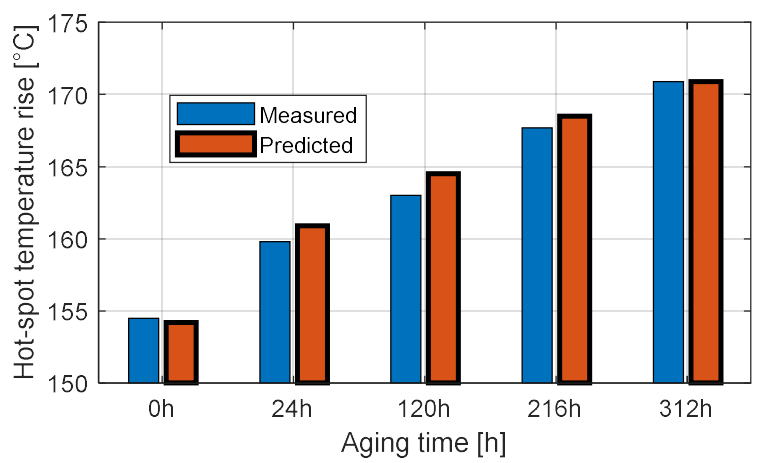

Fig. 10. Comparison between measured and predicted hot-spot temperatures at various thermal aging levels.
TABLE II

Winding Thermal CONDUCTIVITy vs. THermal Aging

\begin{tabular}{cc}
\hline $\begin{array}{c}\text { Thermal exposure } \\
\text { time at } \mathbf{2 3 0}{ }^{\circ} \mathbf{C}\end{array}$ & $\begin{array}{c}\text { Winding Conductivity } \boldsymbol{k}_{\boldsymbol{w}} \\
{[\mathbf{W} / \mathbf{m} / \mathbf{K}]}\end{array}$ \\
\hline $0 h$ (unaged) & 0.295 \\
$24 \mathrm{~h}$ & 0.194 \\
$120 \mathrm{~h}$ & 0.164 \\
$216 \mathrm{~h}$ & 0.154 \\
$312 \mathrm{~h}$ & 0.131 \\
\hline \hline
\end{tabular}

V. $\mathrm{K}_{\mathrm{W}}$ VARIATION AND CUMUlative Aging

Based on the analysis developed in Section III, the variation of the winding thermal conductivity can be now correlated with the cumulative aging of the interturn insulation system. Two cases (i.e. aging temperatures and failure probabilities) are considered, namely $230{ }^{\circ} \mathrm{C}$ at failure probability $50 \%$ (or B50), and $180{ }^{\circ} \mathrm{C}$ at failure probability $10 \%$ (or B10).

For the first analyzed case, the result is presented in a visual manner in Fig. 11 where both insulation's cumulative aging and winding thermal conductivity (at various aging levels) are reported on the same plot. For completeness, the $k_{w}$ values (i.e. scatterplot) are also fitted through a logarithmic curve.

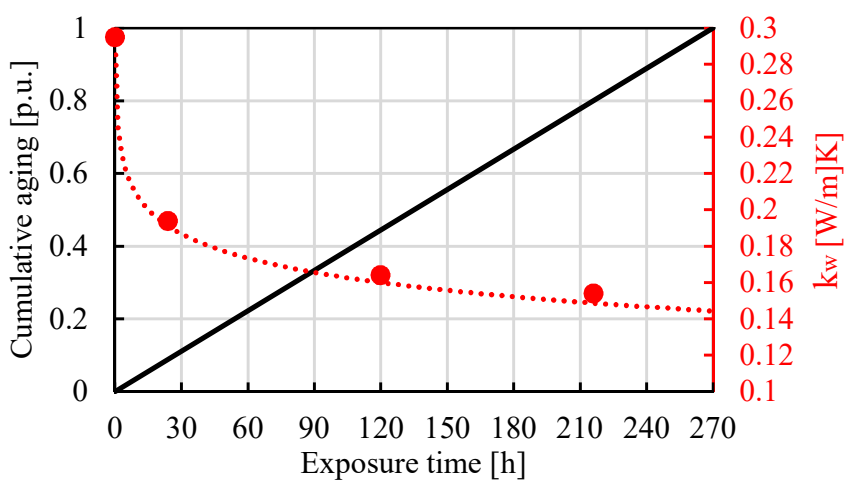

Fig. 11. Winding thermal conductivity vs. cumulative thermal aging at 230 ${ }^{\circ} \mathrm{C}$ and $50 \%$ failure probability.

A similar plot can be developed for the second analysed temperature and failure probability, although in this case it is necessary to uniquely identify the end-of-life point. For doing so, the thermal endurance curve (B10 failure probability) of Fig. 4 is used. The interception of the B10 curve with the 180 ${ }^{\circ} \mathrm{C}$ abscissa, enables the identification of the end-of-life point (i.e. cumulative damage $=1$ ) on the y-axis, that is 20,000 hours. Accordingly, in Fig. 12 both the linear cumulative aging curve and the trend of $k_{w}$ are plotted, similarly to what has been done for $230{ }^{\circ} \mathrm{C}$ aging temperature. For this second presented case, it can be seen that e.g. after 10,000 hours of thermal exposure at $180{ }^{\circ} \mathrm{C}$ (i.e. approximately half life), the winding thermal conductivity drops to $0.16 \mathrm{~W} / \mathrm{m} / \mathrm{K}$, starting from an initial, unaged value of $0.3 \mathrm{~W} / \mathrm{m} / \mathrm{K}$.

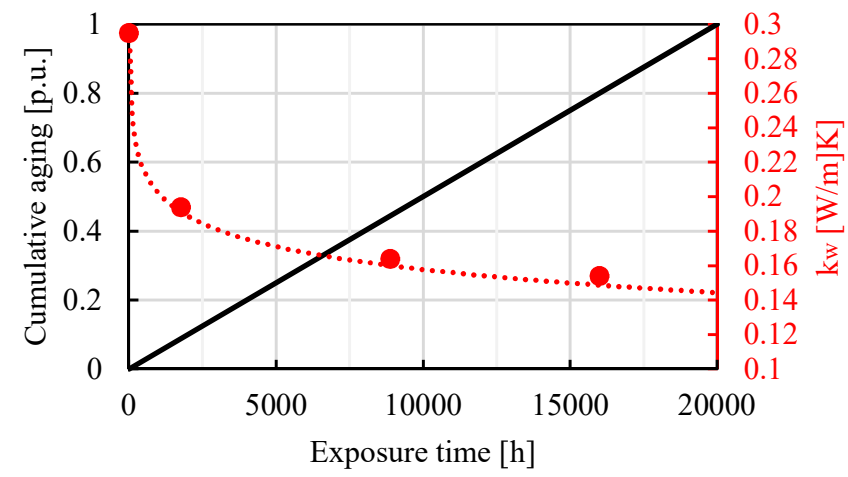

Fig. 12 . Winding thermal conductivity vs. cumulative thermal aging at 180 ${ }^{\circ} \mathrm{C}$ and $10 \%$ failure probability. 
With the purpose of generalizing the obtained results, the normalized (with respect to its initial, unaged value) thermal conductivity is plotted against the per-unit cumulative aging, as shown in Fig. 13. This allows to repeat the presented analyses for various aging temperatures, end-of-life points and initial value of winding thermal conductivity. For facilitating such a procedure, the equation of the logarithmic fitting curve is also reported in Fig. 13.

Interestingly, from Fig. 13 it can be noted that the winding thermal conductivity tends to drop by ca. $35 \%$ when the insulation's cumulative aging is just 0.1 (i.e. $10 \%$ of the total, "expected" lifetime). Then, its trend stabilizes, although its value monotonically decreases as thermal aging accumulates. Towards the insulation's end-of-life, $k_{w}$ can be as low as half of its initial value. This also means that for a generic low voltage EM, its hot-spot temperature, for a given operating condition (i.e. torque and speed), will tend to increase throughout its lifetime, as a result of its insulation system's thermal aging.

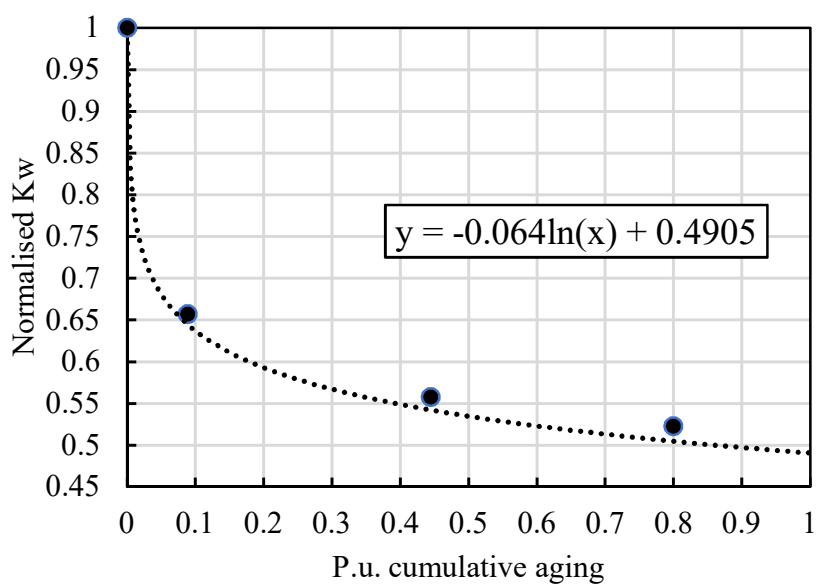

Fig. 13. Variation of the winding equivalent thermal conductivity with the per-unit cumulative thermal aging.

\section{CONCLUSION}

Thermal management is a key part of the design and operations of electrical machines. Various tools, either analytical or based on finite element simulations, can be employed for the thermal analysis of electric motors. The calibration procedure of these tools, necessary for ensuring temperature prediction accuracy, is carried out by assuming that the winding thermal behavior will remain unchanged throughout the whole lifetime of the machine being analyzed.

In this work, it was shown that the equivalent thermal conductivity of the winding, in a typical low voltage machine, is actually strongly influenced by the level of cumulative thermal aging of its insulation system. A Weibull-Bayesian approach was employed for predicting the thermal endurance curve of a case-study prototype. The Arrhenius plot is then used for correlating the level of thermal aging to the variation of winding thermal conductivity, after having performed additional thermal aging campaign on suitable prototypes. It is noted that even in a relatively-new insulation system (i.e. $\approx 10 \%$ cumulative aging), the winding thermal conductivity can drop by as much as $30 \%$, with respect to its initial, totallyunaged status.

\section{REFERENCES}

[1] C. Dong, Y. Qian, Y. Zhang, and W. Zhuge, "A Review of Thermal Designs for Improving Power Density in Electrical Machines," IEEE Transactions on Transportation Electrification, pp. 1-1, 2020.

[2] H. Zhang et al., "Thermal Model Approach to Multisector Three-Phase Electrical Machines," IEEE Transactions on Industrial Electronics, pp. $1-1,2020$

[3] P. Pescetto, S. Ferrari, G. Pellegrino, E. Carpaneto, and A. Boglietti, "Winding Thermal Modeling and Parameters Identification for Multithree Phase Machines Based on Short-Time Transient Tests," IEEE Transactions on Industry Applications, vol. 56, no. 3, pp. 24722480, 2020.

[4] I. Petrov, P. M. Lindh, M. Niemela, E. Scherman, O. Wallmark, and J. J. Pyrhonen, "Investigation of a Direct Liquid Cooling System in a Permanent Magnet Synchronous Machine," IEEE Transactions on Energy Conversion, pp. 1-1, 2019.

[5] V. Madonna, A. Walker, P. Giangrande, G. Serra, C. Gerada, and M. Galea, "Improved Thermal Management and Analysis for Stator EndWindings of Electrical Machines," IEEE Transactions on Industrial Electronics, vol. 66, no. 7, pp. 5057-5069, 2019.

[6] F. Marcolini, G. D. Donato, and F. Caricchi, "Direct Oil Cooling of EndWindings in Torus-Type Axial-Flux Permanent-Magnet Machines," in 2019 IEEE Energy Conversion Congress and Exposition (ECCE), 2019, pp. 5645-5651.

[7] R. Wrobel and A. Hussein, "A Feasibility Study of Additively Manufactured Heat Guides for Enhanced Heat Transfer in Electrical Machines," IEEE Transactions on Industry Applications, vol. 56, no. 1, pp. 205-215, 2020

[8] V. Madonna, P. Giangrande, and M. Galea, "Introducing Physics of Failure Considerations in the Electrical Machines Design," presented at the IEMDC 2019 - International Electric Machines \& Drives Conference, 2019.

[9] M. Popescu, D. A. Staton, A. Boglietti, A. Cavagnino, D. Hawkins, and J. Goss, "Modern Heat Extraction Systems for Power Traction Machines - A Review," IEEE Transactions on Industry Applications, vol. 52, no. 3, pp. 2167-2175, 2016

[10] V. Madonna, P. Giangrande, A. Walker, and M. Galea, "On the Effects of Advanced End-Winding Cooling on the Design and Performance of Electrical Machines," in 2018 XIII International Conference on Electrical Machines (ICEM), 2018, pp. 311-317.

[11] J. K. Nøland, M. Leandro, J. A. Suul, and M. Molinas, "High-Power Machines and Starter-Generator Topologies for More Electric Aircraft: A Technology Outlook," IEEE Access, pp. 1-1, 2020

[12] V. Madonna, G. Migliazza, P. Giangrande, E. Lorenzani, G. Buticchi, and M. Galea, "The Rebirth of the Current Source Inverter: Advantages for Aerospace Motor Design," IEEE Industrial Electronics Magazine, vol. 13 , no. 4 , pp. $65-76,2019$.

[13] K. Ni et al., "Electrical and Electronic Technologies in More-Electric Aircraft: A Review," IEEE Access, vol. 7, pp. 76145-76166, 2019.

[14] H. Vansompel and P. Sergeant, "Extended End-Winding Cooling Insert for High Power Density Electric Machines With Concentrated Windings," IEEE Transactions on Energy Conversion, vol. 35, no. 2, pp. $948-955,2020$

[15] V. Madonna, P. Giangrande, and M. Galea, "Evaluation of Strand-to-Strand Capacitance and Dissipation Factor in Thermally Aged Enameled Coils for Low voltage Electrical Machines," IET Science, Measurement \& Technology, vol. 13, no. 8, pp. 1170-1777, 2019.

[16] K. N. Gyftakis, P. A. Panagiotou, N. Lophitis, D. A. Howey, and M. D. McCulloch, "Breakdown resistance analysis of traction motor winding insulation under thermal ageing," in 2017 IEEE Energy Conversion Congress and Exposition (ECCE), 2017, pp. 5819-5825

[17] P. Giangrande, V. Madonna, S. Nuzzo, and M. Galea, "Moving Toward a Reliability-Oriented Design Approach of Low-Voltage Electrical Machines by Including Insulation Thermal Aging Considerations," IEEE Transactions on Transportation Electrification, vol. 6, no. 1, pp. $16-27,2020$

[18] N. Simpson, R. Wrobel, and P. H. Mellor, "Estimation of Equivalent Thermal Parameters of Impregnated Electrical Windings," IEEE Transactions on Industry Applications, vol. 49, no. 6, pp. 2505-2515, 2013.

[19] V. Madonna, P. Giangrande, C. Gerada, and M. Galea, "Thermal analysis of fault-tolerant electrical machines for aerospace actuators," IET Electric Power Applications, vol. 13, no. 7, pp. 843-852, 2019.

[20] R. Wrobel, S. J. Williamson, J. D. Booker, and P. H. Mellor, "Characterizing the in situ Thermal Behavior of Selected Electrical Machine Insulation and Impregnation Materials," IEEE Transactions on Industry Applications, vol. 52, no. 6, pp. 4678-4687, 2016.

[21] A. Boglietti, M. Cossale, S. Vaschetto, and T. Dutra, "Winding Thermal Model for Short-Time Transient: Experimental Validation in Operative 
Conditions," IEEE Transactions on Industry Applications, vol. 54, no. 2, pp. 1312-1319, 2018

[22] A. Boglietti, M. Cossale, M. Popescu, and D. A. Staton, "Electrical Machines Thermal Model: Advanced Calibration Techniques," IEEE Transactions on Industry Applications, vol. 55, no. 3, pp. 2620-2628, 2019.

[23] A. Boglietti, M. Cossale, S. Vaschetto, and T. Dutra, "Thermal Conductivity Evaluation of Fractional-Slot Concentrated-Winding Machines," IEEE Transactions on Industry Applications, vol. 53, no. 3, pp. 2059-2065, 2017.

[24] V. Madonna, P. Giangrande, G. Migliazza, G. Buticchi, and M. Galea, "A Time-Saving Approach for the Thermal Lifetime Evaluation of Low Voltage Electrical Machines," IEEE Transactions on Industrial Electronics, pp. 1-1, 2019.

[25] G. Turabee et al., "The Role of Neural Networks in Predicting the Thermal Life of Electrical Machines," IEEE Access, vol. 8, pp. 4028340297, 2020.

[26] M. Ghassemi, "Accelerated insulation aging due to fast, repetitive voltages: A review identifying challenges and future research needs,"
IEEE Transactions on Dielectrics and Electrical Insulation, vol. 26, no. 5, pp. 1558-1568, 2019.

[27] V. Madonna, P. Giangrande, W. Zhao, H. Zhang, C. Gerada, and M. Galea, "On the Design of Partial Discharge-Free Low Voltage Electrical Machines," presented at the IEMDC 2019 - International Electric Machines \& Drives Conference, 2019.

[28] R. B. Abernethy, The New Weibull handbook: reliability and statistical analysis for predicting life, safety, supportability, risk, cost and warranty claims. Dr. Robert B. Abernethy, 2004.

[29] W. B. Nelson, Accelerated testing: statistical models, test plans, and data analysis. John Wiley \& Sons, 2009.

[30] V. Madonna, P. Giangrande, L. Lusuardi, A. Cavallini, C. Gerada, and M. Galea, "Thermal Overload and Insulation Aging of Short Duty Cycle, Aerospace Motors," IEEE Transactions on Industrial Electronics, vol. 67, no. 4, pp. 2618-2629, 2020.

[31] M. Galea, P. Giangrande, V. Madonna, and G. Buticchi, "ReliabilityOriented Design of Electrical Machines: The Design Process for Machines' Insulation Systems MUST Evolve," IEEE Industrial Electronics Magazine, vol. 14, no. 1, pp. 20-28, 2020. 